\title{
A feasibility study of laparoscopic total gastrectomy for clinical stage I gastric cancer: a prospective multi-center phase II clinical trial, KLASS 03
}

\author{
Woo Jin Hyung ${ }^{1} \cdot$ Han-Kwang Yang ${ }^{2} \cdot$ Sang-Uk Han ${ }^{3} \cdot$ Young-Jun Lee ${ }^{4} \cdot J^{\prime}$ oong-Min Park ${ }^{5} \cdot$ Jin Jo Kim ${ }^{6}$. \\ Oh Kyung Kwon ${ }^{7}$. Seong Ho Kong ${ }^{2}$. Hyoung-II Kim ${ }^{1}$ - Hyuk-Joon Lee ${ }^{2}$. Wook Kim ${ }^{8}$. Seung Wan Ryu ${ }^{9}$. \\ Sung-Ho Jin ${ }^{10}$. Sung Jin $\mathrm{Oh}^{11}$. Keun Won Ryu ${ }^{12}$. Min-Chan Kim ${ }^{13}$. Hye-Seong Ahn ${ }^{14}$. Young Kyu Park ${ }^{15}$. \\ Young-Ho Kim ${ }^{16}$. Sun-Hwi Hwang ${ }^{17}$. Jong Won $\mathrm{Kim}^{5}$. Gyu Seok Cho ${ }^{18}$
}

Received: 5 March 2018 / Accepted: 5 August 2018 / Published online: 20 August 2018

(c) The International Gastric Cancer Association and The Japanese Gastric Cancer Association 2018

\begin{abstract}
Background With improved short-term surgical outcomes, laparoscopic distal gastrectomy has rapidly gained popularity. However, the safety and feasibility of laparoscopic total gastrectomy (LTG) has not yet been proven due to the difficulty of the technique. This single-arm prospective multi-center study was conducted to evaluate the use of LTG for clinical stage I gastric cancer.

Methods Between October 2012 and January 2014, 170 patients with pathologically proven, clinical stage I gastric adenocarcinoma located at the proximal stomach were enrolled. Twenty-two experienced surgeons from 19 institutions participated in this clinical trial. The primary end point was the incidence of postoperative morbidity and mortality at postoperative 30 days. The severity of postoperative complications was categorized according to Clavien-Dindo classification, and the incidence of postoperative morbidity and mortality was compared with that in a historical control.

Results Of the enrolled patients, 160 met criteria for inclusion in the full analysis set. Postoperative morbidity and mortality rates reached 20.6\% (33/160) and 0.6\% (1/160), respectively. Fifteen patients (9.4\%) had grade III or higher complications, and three reoperations (1.9\%) were performed. The incidence of morbidity after LTG in this trial did not significantly differ from that reported in a previous study for open total gastrectomy (18\%).

Conclusions LTG performed by experienced surgeons showed acceptable postoperative morbidity and mortality for patients with clinical stage I gastric cancer.
\end{abstract}

Keywords Gastric cancer · Laparoscopy $\cdot$ Total gastrectomy

\section{Introduction}

Laparoscopic distal subtotal gastrectomy for gastric cancer has been widely adopted in recent years, particularly in East Asia [1]. As the number of laparoscopic distal gastrectomies performed has increased, several large-scale randomized clinical trials of laparoscopic applications for gastric cancer have been conducted [2-4]. According to these trials, laparoscopic distal gastrectomy is technically feasible and safe,

Gyu Seok Cho

gschogs@schmc.ac.kr

Extended author information available on the last page of the article and compared to open distal gastrectomy, is less likely to involve complications [5, 6].

Unlike subtotal gastrectomy, laparoscopic total gastrectomy for proximal gastric cancer has been slowly accepted, primarily because of technical difficulties with performing the surgery. During the procedure, lymph node dissection around the distal pancreas and splenic hilum poses a tremendous challenge due to complicated vascular structures and a greater risk of pancreatic injury. Moreover, esophagojejunal anastomosis, which has not yet been standardized, is also considered to be one of the difficult parts. Because of these shortcomings, most surgeons are reluctant to perform laparoscopic total gastrectomy for proximal gastric cancer.

Verifying the safety of laparoscopic total gastrectomy will help widen the application thereof. Although several studies 
have assessed the safety of laparoscopic total gastrectomy [7-12], these have mostly been single-center retrospective studies of a small sample size. To yield robust evidence of the safety and feasibility of laparoscopic total gastrectomy, the Korean Laparoendoscopic Gastrointestinal Surgery Study (KLASS) group proposed a prospective multi-center trial of laparoscopic total gastrectomy for clinical stage I gastric cancer to determine the safety and feasibility of laparoscopic total gastrectomy (KLASS-03 trial). In doing so, we aimed to assess types of postoperative complications and the incidence of 30-day postoperative morbidity and mortality following laparoscopic total gastrectomy. We also sought to compare operative outcomes after laparoscopic total gastrectomy with those reported in a previous study for open total gastrectomy [13].

\section{Methods}

\section{Patients}

We conducted a single-arm prospective multi-center study from October 2012 to January 2014. Inclusion criteria were as follows: patients of ages from 20 to 80 years, the presence of pathologically proven gastric adenocarcinoma, diagnosis of clinical stage IA (cT1N0M0) or IB (cT1N1M0 and cT2N0M0) disease based on the 7th UICC/AJCC TNM staging system, no indication for endoscopic submucosal dissection, Eastern Cooperative Oncology Group (ECOG) performance status $<1$, and an American Society of Anesthesiology (ASA) score < III. We excluded those who had synchronous or metachronous malignant tumors in other organs within the past 5 years, a history of upper abdominal laparotomy, a history of any gastric surgery, and/or lymph node enlargement in the splenic hilum (lymph node station number 10) on a computed tomography scan.

When patients met the selection criteria, they were informed of the study objectives, and informed consent was obtained prior to registry with the data center. A serial number was assigned by the data center according to the order of registration, and all surgeries were to be performed within 30 days. The institutional review boards of all participating centers approved this study. This study was registered at ClinicalTrials.gov (ClinicalTrials.gov Identifier: NCT01584336).

\section{Surgeons}

Twenty-two surgeons from 19 centers participated in this clinical trial. All participating institutions perform more than 80 gastrectomies per year for gastric cancer. All participating surgeons had experience of both laparoscopic and open gastrectomy procedures more than 50, respectively. During the preparation period for KLASS-03 trial, we held several investigator meetings in which all participating surgeons reviewed their operation videos altogether and made an agreement on esophagojejunostomy techniques among surgeons. All surgeons already had performed enough number of laparoscopic subtotal gastrectomy or total gastrectomy for stage I gastric cancer. All participating surgeons are specialized surgeons for gastric cancer surgery and working at the high-volume center.

\section{Operative interventions}

Lymph node dissection was performed in accordance with the following principles: D1 + lymph node dissection to be performed for clinical stage IA disease and D2 lymph node dissection (8a, 9, 11p, 11d, and 12a lymph node stations), except lymph node station number 10 , to be performed for clinical stage IB disease. D2 lymphadenectomy including the lymph nodes in the splenic hilum (lymph node station number 10) was performed in cases with suspicious serosal involvement or metastasis to the splenic hilar lymph node in the laparoscopic view.

Reconstruction was achieved according to the clinical practice of each institution. Either extracorporeal or intracorporeal anastomosis was allowed for reconstruction. Any type of stapled anastomosis using either a circular or linear staplers was allowed for the esophagojejunostomy. A drainage tube was inserted into the gastric bed along the upper border of the pancreas. We measured size of mini-laparotomy for anastomosis and specimen delivery as the length of the skin incision.

\section{Postoperative management}

For postoperative management, a standardized clinical pathway was applied, including dietary build-up and blood and radiography examinations. If a patient tolerated three meals of a soft diet without gastrointestinal symptoms and if their vital signs had stabilized, they were advised to be discharged from the hospital. Adjuvant chemotherapy was recommended when pathological results confirmed stage II or more advanced cancer.

\section{Outcomes}

We assessed patient disease history, ECOG performance status, and ASA score preoperatively. We also collected data on total operation time, anastomosis time, type of esophagojejunal reconstruction, location and length of a mini-laparotomy, extent of lymph node dissection, estimated blood loss volume, and intraoperative complications as operative findings. The anastomosis time was defined as the time for all anastomosis-related procedures, including esophagojejunostomy 
and jejunojejunostomy, jejunal stump closure, and mesenteric defect repair. Estimated blood loss was measured by checking suction volumes and gauze weights during surgery. Intraoperative complications were classified as massive bleeding, vascular injury, other organ injuries around the stomach, anastomosis failure, hypercarbia, and any added techniques or delayed incidents, including additional treatments performed during surgery.

Postoperative complications that occurred within 30 days after surgery were assessed according to Clavien-Dindo classification [14], and readmission was recorded along with the reason thereof. Postoperative mortality was defined as any death within 30 days after surgery and death related to complications regardless of timing. Before beginning this study, we consulted with the Italian Gastric Cancer Study Group, which previously conducted a randomized control trial study for open total gastrectomy, to establish criteria for and types of complications used in their study, with which we sought to compare [13]. Complications after surgery were classified largely into systemic and local complications
(Table 1). We also assessed long-term mortality rates of laparoscopic total gastrectomy to provide baseline data for a phase-III study through which to prove the oncological safety thereof.

\section{Sample size}

This study was designed to verify the safety of laparoscopic total gastrectomy by proving the non-inferiority thereof in relation to the incidence of complications after an open conventional approach based on a historical control. For the past 10 years, we found only one multi-center prospective study reporting a complication rate of $18 \%$ (12 of 66 patients) following open total gastrectomy [13]. Thus, we used the $18 \%$ complication rate as the comparative historical control. To calculate the limitation of non-inferiority, we collected 16 studies on complications after open total gastrectomy published in English for the past 10 years and conducted a metaanalysis $[8,9,13,15-27]$. As a result, the $95 \%$ confidence interval of the upper limit was determined to be $26.6 \%$, and

Table 1 Definition of complications

\begin{tabular}{|c|c|}
\hline \multicolumn{2}{|l|}{ Systemic complications } \\
\hline Pulmonary & $\begin{array}{l}\text { Additional treatments were required, such as therapeutic antibiotics, percutaneous drainage, or mechanical ventila- } \\
\text { tion due to atelectasis, pleural effusion, empyema, pneumonia, and pneumothorax accompanied by symptoms, } \\
\text { such as febricity and dyspnea }\end{array}$ \\
\hline Urinary & Additional treatments were required, such as catheter re-insertion due to dysuria and urinary retention \\
\hline Cardiac & Treatments were required due to symptoms of heart failure after surgery, myocardial ischemia, or infarction \\
\hline Systemic infection & $\begin{array}{l}\text { Symptoms of fever due to infection, increased number of neutrophils, and pathogen cultures from a blood culture } \\
\text { examination }\end{array}$ \\
\hline \multicolumn{2}{|l|}{ Local complications } \\
\hline Wound & $\begin{array}{l}\text { Extended hospitalization due to surgical wound infection and additional treatment other than simple disinfection } \\
\text { was required }\end{array}$ \\
\hline Ascites & $\begin{array}{l}\text { Additional treatments were required due to retention of intraperitoneal fluid or abdominal distension after an } \\
\text { abdominal ultrasound examination or tomography }\end{array}$ \\
\hline Postoperative ileus & Fasting more than 7 days after surgery due to enteroplegia or drainage that occurred through the nasogastric tube \\
\hline Abdominal abscess & $\begin{array}{l}\text { Intra-abdominal abscesses or infected body fluids were found after an abdominal ultrasound examination or } \\
\text { tomography such that the additional use of antibiotics or additional treatment was required, such as drainage or } \\
\text { reoperation }\end{array}$ \\
\hline Pancreatic leakage & $\begin{array}{l}\text { Amylase level in peritoneal fluid discharged through the drainage tube was }>1,000 \mathrm{IU} \text {, protein } \geq 3.0 \mathrm{~g} / \mathrm{dL} \text { : amylase } \\
\text { and protein levels in peritoneal fluid discharged through the drainage tube were routinely measured on postopera- } \\
\text { tive day } 4\end{array}$ \\
\hline Acute pancreatitis & $\begin{array}{l}\text { Symptoms, such as abdominal pain or fever after surgery, accompanied by abdominal CT results or blood amylase } \\
\text { levels greater than three times the normal level }\end{array}$ \\
\hline Intra-abdominal bleeding & $\begin{array}{l}\text { Bleeding through the drainage tube installed inside the abdominal cavity and additional treatments required, such as } \\
\text { blood transfusion, reoperation, and embolization due to bleeding, confirmed through imaging tests accompanied } \\
\text { by a decrease in serum hemoglobin }\end{array}$ \\
\hline Anastomotic bleeding & $\begin{array}{l}\text { Additional treatments required, such as transfusion, endoscopic surgery, and reoperation, due to a decrease in } \\
\text { plasma hemoglobin level caused by anastomotic bleeding confirmed through endoscopy }\end{array}$ \\
\hline Anastomotic stenosis & $\begin{array}{l}\text { Fasting or drainage, endoscopic intervention, and reoperation required due to food discharge difficulties below the } \\
\text { anastomotic site after surgery }\end{array}$ \\
\hline Anastomotic leakage & Leakage at the anastomotic site confirmed clinically and radiologically after surgery \\
\hline Duodenal stump leakage & Duodenal suture leakage confirmed clinically and radiologically \\
\hline Miscellaneous & Additional treatment required due to patient complaints about symptoms other than those listed above \\
\hline
\end{tabular}


the threshold value was $8 \%$. Thus, the sample size for the present trial was estimated at 168 patients, with a $15 \%$ dropout rate, a significance level of 0.05 , and a statistical power of 0.8 .

\section{Statistics}

A full analysis set (FAS) was included to assess the primary outcome in the current trial. The FAS was designated as patients who completed their assigned treatment, excluding those who declined to participate in the study after giving consent and being registered and those who did not undergo total gastrectomy. Only the major and most severe Clavien-Dindo classification grade for each patient was used in determining complication rates. All $p$ values $<0.05$ were considered significant. All statistical analyses were conducted using SPSS software, ver. 18.0 (SPSS Inc., Chicago, Il, USA).

\section{Results}

\section{Patient characteristics (Table 2)}

In total, 170 patients were registered from October 2012 to January 2014. Of these, 160 met the FAS criteria. As shown in Fig. 1, the 10 patients were excluded for the following reasons: one enrollment violation, one withdrawal from the study after giving signed informed consent, and eight other types of gastrectomy, including one laparoscopic proximal gastrectomy and seven laparoscopic distal gastrectomies.

More than twice as many male patients than female patients were enrolled, and $50.2 \%$ of all patients had comorbidities, including $15.6 \%$ who had more than two associated diseases. Eleven patients (6.9\%) were treated by endoscopic submucosal dissection initially and underwent subsequent laparoscopic total gastrectomy due to tumor invasion to submucosal layers or resection margins. All patients were stage I clinically; none had lesions extending to the esophagus; and seven patients (4.4\%) had lesions involving the gastroesophageal junction. Final pathological examination revealed stage I disease in $88.1 \%$ of patients and stage II disease in the remaining $11.9 \%$ (19 cases).

\section{Operative outcomes (Table 3)}

The mean operation time was $226.7 \mathrm{~min}$, and the mean anastomosis time was $50.7 \mathrm{~min}$ (22.4\% of the total operation time). Esophagojejunostomy was performed extracorporeally through a mini-laparotomy in 45 patients (28.1\%). For extracorporeal anastomosis, the mini-laparotomy incision was made in the epigastrium in 39 patients, the left upper abdomen in five, and the umbilicus in one. Meanwhile, for
Table 2 Patient clinical characteristics

\begin{tabular}{|c|c|c|}
\hline Variable & $N=160$ & $(\%)$ \\
\hline Age (years) & $59.2 \pm 10.2$ & \\
\hline \multicolumn{3}{|l|}{ Gender } \\
\hline Male & 115 & 71.9 \\
\hline Female & 45 & 28.1 \\
\hline Body mass index $\left(\mathrm{kg} / \mathrm{m}^{2}\right)$ & $24.0 \pm 2.9$ & \\
\hline \multicolumn{3}{|l|}{ Comorbidities } \\
\hline None & 78 & 48.8 \\
\hline Single & 57 & 35.6 \\
\hline Multiple & 25 & 15.6 \\
\hline \multicolumn{3}{|l|}{ ASA score } \\
\hline 1 & 72 & 45.0 \\
\hline 2 & 81 & 50.6 \\
\hline 3 & 7 & 4.4 \\
\hline \multicolumn{3}{|l|}{ Previous ESD } \\
\hline No & 149 & 93.1 \\
\hline Yes & 11 & 6.9 \\
\hline \multicolumn{3}{|l|}{ Clinical stage } \\
\hline IA & 133 & 83.1 \\
\hline IB & 27 & 16.9 \\
\hline \multicolumn{3}{|l|}{ Tumor location } \\
\hline Esophagus involved & 0 & 0 \\
\hline Esophagojejunal junction involved & 7 & 4.4 \\
\hline Subcardial & 153 & 95.6 \\
\hline \multicolumn{3}{|l|}{ Type of esophagojejunostomy } \\
\hline Extracorporeal & 45 & 28.1 \\
\hline Intracorporeal & 115 & 71.9 \\
\hline \multicolumn{3}{|l|}{ Stapler for esophagojejunostomy } \\
\hline Circular & 109 & 68.1 \\
\hline Linear & 51 & 31.9 \\
\hline \multicolumn{3}{|l|}{ Type of jejunojejunostomy } \\
\hline Extracorporeal & 110 & 68.8 \\
\hline Intracorporeal & 50 & 31.2 \\
\hline \multicolumn{3}{|l|}{ Method of jejunojejunostomy } \\
\hline Hand-sewn & 40 & 25.0 \\
\hline Linear & 99 & 61.9 \\
\hline Circular & 21 & 13.1 \\
\hline \multicolumn{3}{|l|}{ Extent of LND } \\
\hline D1 & 1 & 0.6 \\
\hline $\mathrm{D} 1+$ & 98 & 61.3 \\
\hline D2 -\#10 & 47 & 29.4 \\
\hline D2 & 14 & 8.8 \\
\hline
\end{tabular}

specimen retrieval during intracorporeal esophagojejunostomy, most mini-laparotomy incisions were made through the umbilicus $(n=73)$ or left abdomen $(n=52)$. Mean BMI of patients undergone extracorporeal was 23.7 (range 19.0-28.9) similar to that of patients undergone intracorporeal anastomosis was 24.2 (range 17.3-33.1, $p=0.314$ ). The medians of incision length for extra- and intracorporeal 


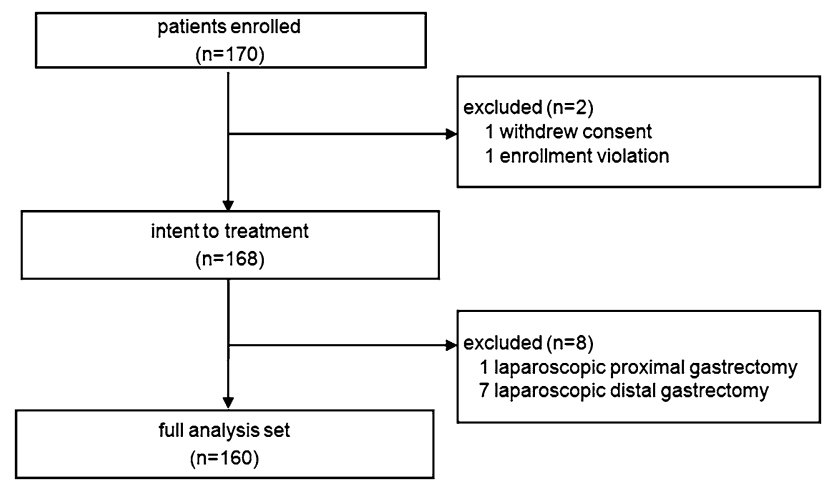

Fig. 1 Study flow chart

anastomosis were $9 \mathrm{~cm}$ (range $2-15 \mathrm{~cm}$ ) and $3.5 \mathrm{~cm}$ (range $2-8 \mathrm{~cm}$ ), respectively. The mean length of mini-laparotomy for extracorporeal anastomosis was significantly longer than that of intracorporeal anastomosis $(3.8$ versus $8.6 \mathrm{~cm}$, $p<0.001)$.

Ninety-nine patients $(61.9 \%)$ underwent D1 + dissection or less, and 14 (8.8\%) underwent D2 lymph node dissection including lymph node station number 10 . No open conversions were reported, and 12 intraoperative complications were recorded in 10 patients. The intraoperative complications included two splenic vessel injuries, two cases of $>30 \%$ splenic ischemia, two cases of splenic capsular tearing, three cases of esophagojejunostomy insufficiency necessitating a laparoscopic reinforce suture, one transverse colon injury, one jejunojejunostomy-site ischemia, and one subcutaneous emphysema.

\section{Postoperative complications (Table 4)}

In total, 33 patients (20.6\%) experienced complications within 30 days after surgery, including one $(0.6 \%)$ postoperative mortality. The complication rate of $20.6 \%$ (33 out of 160) in our study was not statistically different from that of $18.2 \%$ (12 out of 66) in the historical control $(p=0.814$ ). Fifteen patients (9.4\%) exhibited grade III or higher complications according to Clavien-Dindo classification, including three reoperations. Eight patients were re-admitted to the hospital within 9-27 days after discharge. The most common complications were pulmonary disease $(n=6,3.8 \%)$ intra-abdominal abscess $(n=5,3.1 \%)$, wound infection $(n=5,3.1 \%)$, and anastomotic leakage $(n=3,1.9 \%)$. The complication rates of patients who underwent extracorporeal and intracorporeal anastomosis were 28.9\% (13/45) and $19.1 \%(22 / 115)$, respectively $(p=0.204)$. Two of the three reoperations were performed due to adhesions around the jejunojejunostomy at 2 weeks after discharge, and a duodenojejunostomy was conducted in both patients. The other reoperation was a distal esophagectomy for leakage at the
Table 3 Surgical and pathological outcomes

\begin{tabular}{|c|c|c|}
\hline Variable & $N=160$ & $(\%)$ \\
\hline Operation time $(\min )$ & $226.7 \pm 64.5$ & \\
\hline Anastomotic time (min) & $50.5 \pm 23.6$ & \\
\hline Intraoperative complications & 10 & 6.3 \\
\hline Estimated blood loss (mL) & $135.5 \pm 185.8$ & \\
\hline Intraoperative transfusions & 2 & 1.3 \\
\hline Open conversion & 0 & 0 \\
\hline Time to first flatus (days) & $3.5 \pm 1.0$ & \\
\hline Time to soft diet (days) & $5.7 \pm 3.8$ & \\
\hline Hospital stay (days) & $9.7 \pm 7.1$ & \\
\hline \multicolumn{3}{|l|}{ Postoperative morbidities } \\
\hline Present & 33 & 20.6 \\
\hline Clavien-Dindo $\geq 3$ & 15 & 9.4 \\
\hline Postoperative mortality & 1 & 0.6 \\
\hline Readmission after discharge & 8 & 5.0 \\
\hline Reoperation & 3 & 1.9 \\
\hline Tumor size $(\mathrm{mm})$ & $30.3 \pm 20.8$ & \\
\hline \multicolumn{3}{|l|}{ Number of tumors } \\
\hline Single & 145 & 90.6 \\
\hline Multiple & 15 & 9.4 \\
\hline Proximal margin $(\mathrm{mm})$ & $33.5 \pm 25.5$ & \\
\hline Number of harvested lymph nodes & $43.5 \pm 14.9$ & \\
\hline \multicolumn{3}{|l|}{ Pathologic T stage } \\
\hline T0 & 1 & 0.6 \\
\hline T1a & 71 & 44.4 \\
\hline $\mathrm{T} 1 \mathrm{~b}$ & 65 & 40.6 \\
\hline $\mathrm{T} 2$ & 13 & 8.1 \\
\hline T3 & 7 & 4.4 \\
\hline $\mathrm{T} 4 \mathrm{a}$ & 3 & 1.9 \\
\hline \multicolumn{3}{|l|}{ Pathologic N stage } \\
\hline No & 143 & 89.4 \\
\hline N1 & 8 & 5.0 \\
\hline $\mathrm{N} 2$ & 5 & 3.1 \\
\hline N3a & 3 & 1.9 \\
\hline $\mathrm{N} 3 \mathrm{~b}$ & 1 & 0.6 \\
\hline \multicolumn{3}{|l|}{ AJCC stage (7th) } \\
\hline IA & 121 & 75.6 \\
\hline IB & 20 & 12.5 \\
\hline IIA & 11 & 6.9 \\
\hline IIB & 8 & 5.0 \\
\hline
\end{tabular}

esophagojejunostomy site, which resulted in mortality. The patient experienced mortality was a 62-year-old male who underwent laparoscopic total gastrectomy with intracorporeal esophagojejunostomy. On postoperative day 2, the patient had high fever accompanied with dyspnea and a chest computed tomography demonstrated postoperative pneumonia and early stage acute respiratory distress syndrome. Then, the patient was transferred to intensive care unit and treated conservatively on the same day. During the 
Table 4 Postoperative complications

\begin{tabular}{|c|c|c|c|c|}
\hline & Type of complication & Clavien-Dindo $<3$ & Clavien-Dindo $\geq 3$ & All \\
\hline \multirow[t]{5}{*}{ Systemic complications } & Pulmonary & 4 & 2 & $6(3.8 \%)$ \\
\hline & Urinary & 2 & & $2(1.3 \%)$ \\
\hline & Cardiac & & & - \\
\hline & Systemic infection & & & - \\
\hline & Subtotal & 6 & 2 & $8(5.0 \%)$ \\
\hline \multirow[t]{14}{*}{ Local complications } & Wound & 3 & 2 & $5(3.1 \%)$ \\
\hline & Ascites & & 1 & $1(0.6 \%)$ \\
\hline & Postoperative ileus & 1 & & $1(0.6 \%)$ \\
\hline & Postoperative adhesion & & 2 & $2(1.3 \%)$ \\
\hline & Abdominal abscess & 3 & 2 & $5(3.1 \%)$ \\
\hline & Omental infarction & 1 & & $1(0.6 \%)$ \\
\hline & Pancreatic leakage & 2 & & $2(1.3 \%)$ \\
\hline & Acute pancreatitis & 1 & & $1(0.6 \%)$ \\
\hline & Intra-abdominal bleeding & & & - \\
\hline & Anastomotic bleeding & 1 & 1 & $2(1.3 \%)$ \\
\hline & Anastomotic stenosis & & & - \\
\hline & Anastomotic leakage $^{a}$ & & 3 & $3(1.9 \%)$ \\
\hline & Duodenal stump leakage & & 2 & $2(1.3 \%)$ \\
\hline & Subtotal & 12 & 13 & $25(15.6 \%)$ \\
\hline Total & Total & $18(11.2 \%)$ & $15(9.4 \%)$ & $33(20.6 \%)$ \\
\hline
\end{tabular}

${ }^{\mathrm{a} O n e}$ mortality

recovery in the intensive care unit, the feature and color of drainage tube had changed and esophagojejunostomy site leakage was suspected on postoperative day 19. After confirmation of the esophagojejunostomy site leakage, endoscopy was performed and vacuum treatment was applied. However, endoscopic vacuum treatment was not effective and septic condition was worsened. Right transthoracic distal esophagectomy, cervical diverting esophagostomy, segmental resection of jejunal Roux limb, and feeding jejunostomy was performed on postoperative day 30 . However, even after the reoperation, sepsis was more aggravated and resulted in mortality on postoperative day 33 .

\section{Discussion}

This prospective multi-center study on laparoscopic total gastrectomy recorded a postoperative complication rate of $20.6 \%$, which is similar to the reference value of $18 \%$ for open total gastrectomy reported in an Italian randomized prospective study [13]. The complication rate recorded in the present trial was not inferior to that in the previous study according to the predetermined threshold value of $8 \%$. Since we used the same criteria for and types of complications, except for wound complications, as those in the Italian randomized prospective study, we could directly compare our results with those of the Italian trial. Our study recorded a mortality rate of $0.6 \%$ which is lower than the in-hospital mortality rate of $8 \%$ (5 of 66 patients) after open total gastrectomy in the Italian study. However, since the historical control had more advanced stages than our study, we cannot exclude a higher risk of complications and mortality in the historical control than in our study.

Postoperative complications after total gastrectomy are generally known to be higher than those after other types of gastrectomy for gastric cancer. The complication rate in this study was much higher than that after laparoscopic distal gastrectomy in the KLASS-01 trial, which evaluated laparoscopic distal subtotal gastrectomy for early gastric cancer [6]. The differences in complication type and incidence between laparoscopic total and distal gastrectomy likely stem from the wider extent of lymph node dissection, especially around the pancreas tail and splenic hilum, and greater difficulties in achieving anastomosis during total gastrectomy. Consequently, these features lead to more infectious complications in the abdomen, such as intra-abdominal abscesses, pancreatic fistula, and anastomotic leakages. For comparison, although the incidence of anastomosis-related complications, such as leakage, bleeding, and stenosis, after laparoscopic distal gastrectomy was $1.6 \%$ in the KLASS-01 trial, after laparoscopic total gastrectomy was $3.2 \%$ in the current study. The rate of pancreas-related complications, such as pancreatitis or pancreatic leakage, was $0.1 \%$ for laparoscopic distal gastrectomy, but $1.9 \%$ for laparoscopic total gastrectomy in this trial. Intra-abdominal abscesses were recorded in $0.9 \%$ after laparoscopic distal gastrectomy 
and in $3.1 \%$ after laparoscopic total gastrectomy. Although these results cannot be compared statistically due to different surgical extents and treatment strategies, we deduced that anastomosis poses a greater challenge in laparoscopic total gastrectomy that pancreatic injuries occur more frequently during lymph node dissection along the upper border of the pancreas, and that intra-abdominal abscesses more often develop after laparoscopic total gastrectomy. These findings reflect the greater procedural complexity of laparoscopic total gastrectomy in comparison to laparoscopic distal gastrectomy.

Compared to laparoscopic distal gastrectomy in the KLASS-01 trial, laparoscopic total gastrectomy in the present trial showed an operation time longer by $42.6 \mathrm{~min}$ and an estimated blood loss larger by $25.5 \mathrm{~mL}$. The longer operation time and larger volume of estimated blood loss during laparoscopic total gastrectomy would be related to more extended lymph node dissection, including dissection along the splenic vessels, and the more complex reconstruction process. Indeed, six of the 12 intraoperative complications were vascular injuries, especially in splenic vessels. In addition, the other three intraoperative complications were associated with the esophagojejunostomy. Additionally, since we did not include incision length as a criterion for open conversion, skin incision larger than $10 \mathrm{~cm}$ was made for some patients underwent extracorporeal anastomosis. Although majority of the esophagojejunal anastomosis was done intracorporeally with a relatively small incision, incision length should be considered as an important factor to evaluate the success of laparoscopic procedure.

Although the results of our study seem to be acceptable, there might be an issue regarding the quality of surgeries and validation of participating surgeons before enrollment in the current multicenter clinical trial. As in previously conducted KLASS trials, the current study applied the same criteria for surgeons and institutions for participation in the study. All 22 surgeons who participated in the current study were qualified in laparoscopic gastrectomy, as well as open conventional approaches, and had overcome the learning curve for laparoscopic gastrectomy. Most had participated in the KLASS-01 and KLASS-02 clinical trials. Therefore, unlike other surgical trials, the bias generated by a lack of experience among surgeons could be minimized.

In this study, we conducted a single-arm prospective study of laparoscopic total gastrectomy to compare its shortterm results with those reported for open total gastrectomy in previous studies and to determine its technical feasibility and safety. The results of our study emphasize the technical safety of laparoscopic total gastrectomy when it was performed by experienced hands. However, no randomization was performed in the current study, and only one welldesigned randomized study in the past decade was available with which to compare our results. Although our study was a single-arm prospective study, our results can be used as background data for future randomized clinical trials to evaluate the oncological safety of laparoscopic total gastrectomy for gastric cancer or for other studies comparing surgical techniques other than laparoscopic total gastrectomy. Based on our results, laparoscopic total gastrectomy was found to be technically feasible and could be performed safely. As a result, KLASS-05 trial that compares the short-term and long-term results of laparoscopic proximal gastrectomy to those of laparoscopic total gastrectomy is ongoing. In addition, KLASS-01 trial showed that there was no difference in terms of long-term survival between open subtotal gastrectomy and laparoscopic subtotal gastrectomy for stage I gastric cancer. Our KLASS group has started the KLASS06 trial which is the phase-III randomized trial comparing between the open and laparoscopic total gastrectomy for advanced gastric cancer.

\section{Conclusions}

We have addressed the safety and feasibility of laparoscopic total gastrectomy for proximal stage I gastric cancer. Although we did not directly compare results with a control group by randomization, our results suggest that stage I gastric cancer can be a potential candidate for laparoscopic surgery. Further studies should be conducted to investigate long-term survival and recurrence patterns after laparoscopic total gastrectomy, as they are important elements for assessing the oncological safety of any surgical approach.

\section{Compliance with ethical standards}

Conflict of interest All authors declare that they have no conflicts of interest.

Ethical standards Each centre's institutional review board or independent ethics committee approved the study. All procedures followed the guiding principles of the Declaration of Helsinki and the Good Clinical Practice Guidelines of the International Conference on Harmonization. All patients provided written informed consent.

\section{References}

1. Kitano S, Iso Y, Moriyama M, Sugimachi K. Laparoscopy-assisted Billroth I gastrectomy. Surg Laparosc Endosc. 1994;4:146-8.

2. Kim HH, Hyung WJ, Cho GS, Kim MC, Han SU, Kim W, et al. Morbidity and mortality of laparoscopic gastrectomy versus open gastrectomy for gastric cancer: an interim report-a phase III multicenter, prospective, randomized Trial (KLASS Trial). Ann Surg. 2010;251:417-20.

3. Katai H, Sasako M, Fukuda H, Nakamura K, Hiki N, Saka M, et al. Safety and feasibility of laparoscopy-assisted distal gastrectomy with suprapancreatic nodal dissection for clinical stage I 
gastric cancer: a multicenter phase II trial (JCOG 0703). Gastric Cancer. 2010;13:238-44.

4. Kim HH, Han SU, Kim MC, Hyung WJ, Kim W, Lee HJ, et al. Long-term results of laparoscopic gastrectomy for gastric cancer: a large-scale case-control and case-matched Korean multicenter study. J Clin Oncol. 2014;32:627-33.

5. Inaki N, Etoh T, Ohyama T, Uchiyama K, Katada N, Koeda K, et al. A multi-institutional, prospective, phase II feasibility study of laparoscopy-assisted distal gastrectomy with D2 lymph node dissection for locally advanced gastric cancer (JLSSG0901). World J Surg. 2015;39:2734-41.

6. Kim W, Kim HH, Han SU, Kim MC, Hyung WJ, Ryu SW, et al. Decreased morbidity of laparoscopic distal gastrectomy compared with open distal gastrectomy for stage I gastric cancer: shortterm outcomes from a multicenter randomized controlled trial (KLASS-01). Ann Surg. 2016;263:28-35.

7. Jeong GA, Cho GS, Kim HH, Lee HJ, Ryu SW, Song KY. Laparoscopy-assisted total gastrectomy for gastric cancer: a multicenter retrospective analysis. Surgery. 2009;146:469-74.

8. Dulucq JL, Wintringer P, Stabilini C, Solinas L, Perissat J, Mahajna A. Laparoscopic and open gastric resections for malignant lesions: a prospective comparative study. Surg Endosc. 2005;19:933-8.

9. Mochiki E, Toyomasu Y, Ogata K, Andoh H, Ohno T, Aihara $\mathrm{R}$, et al. Laparoscopically assisted total gastrectomy with lymph node dissection for upper and middle gastric cancer. Surg Endosc. 2008;22:1997-2002.

10. Du J, Zheng J, Li Y, Li J, Ji G, Dong G, et al. Laparoscopyassisted total gastrectomy with extended lymph node resection for advanced gastric cancer-reports of 82 cases. Hepatogastroenterology. 2010;57:1589-94.

11. Haverkamp L, Weijs TJ, van der Sluis PC, van der Tweel I, Ruurda JP, van Hillegersberg R. Laparoscopic total gastrectomy versus open total gastrectomy for cancer: a systematic review and metaanalysis. Surg Endosc. 2013;27:1509-20.

12. Chen K, Xu XW, Zhang RC, Pan Y, Wu D, Mou YP. Systematic review and meta-analysis of laparoscopy-assisted and open total gastrectomy for gastric cancer. World J Gastroenterol. 2013;19:5365-76.

13. Degiuli M, Sasako M, Ponti A. Morbidity and mortality in the Italian Gastric Cancer Study Group randomized clinical trial of D1 versus D2 resection for gastric cancer. Br J Surg. 2010;97:643-9.

14. Dindo D, Demartines N, Clavien PA. Classification of surgical complications: a new proposal with evaluation in a cohort of 6336 patients and results of a survey. Ann Surg. 2004;240:205-13.
15. Yoo CH, Sohn BH, Han WK, Pae WK. Long-term results of proximal and total gastrectomy for adenocarcinoma of the upper third of the stomach. Cancer Res Treat. 2004;36:50-5.

16. Yu W, Choi GS, Chung HY. Randomized clinical trial of splenectomy versus splenic preservation in patients with proximal gastric cancer. Br J Surg. 2006;93:559-63.

17. Kim JH, Park SS, Kim J, Boo YJ, Kim SJ, Mok YJ, et al. Surgical outcomes for gastric cancer in the upper third of the stomach. World J Surg. 2006;30:1870-6. (discussion 7-8).

18. Topal B, Leys E, Ectors N, Aerts R, Penninckx F. Determinants of complications and adequacy of surgical resection in laparoscopic versus open total gastrectomy for adenocarcinoma. Surg Endosc. 2008;22:980-4.

19. Gong DJ, Miao CF, Bao Q, Jiang M, Zhang LF, Tong XT, et al. Risk factors for operative morbidity and mortality in gastric cancer patients undergoing total gastrectomy. World J Gastroenterol. 2008;14:6560-3.

20. An JY, Youn HG, Choi MG, Noh JH, Sohn TS, Kim S. The difficult choice between total and proximal gastrectomy in proximal early gastric cancer. Am J Surg. 2008;196:587-91.

21. Kawamura H, Yokota R, Homma S, Kondo Y. Comparison of invasiveness between laparoscopy-assisted total gastrectomy and open total gastrectomy. World J Surg. 2009;33:2389-95.

22. Sakuramoto S, Kikuchi S, Futawatari N, Katada N, Moriya H, Hirai K, et al. Laparoscopy-assisted pancreas- and spleen-preserving total gastrectomy for gastric cancer as compared with open total gastrectomy. Surg Endosc. 2009;23:2416-23.

23. Oh SJ, Hyung WJ, Li C, Song J, Kang W, Rha SY, et al. The effect of spleen-preserving lymphadenectomy on surgical outcomes of locally advanced proximal gastric cancer. J Surg Oncol. 2009;99:275-80.

24. Sasada S, Ninomiya M, Nishizaki M, Harano M, Ojima Y, Matsukawa $\mathrm{H}$, et al. Frequency of lymph node metastasis to the splenic hilus and effect of splenectomy in proximal gastric cancer. Anticancer Res. 2009;29:3347-51.

25. Koksoy FN, Gonullu D, Catal O, Kuroglu E. Risk factors for operative mortality and morbidity in gastric cancer undergoing D2-gastrectomy. Int J Surg. 2010;8:633-5.

26. Kim MG, Kim BS, Kim TH, Kim KC, Yook JH. The effects of laparoscopic assisted total gastrectomy on surgical outcomes in the treatment of gastric cancer. J Korean Surg Soc. 2011;80:245-50.

27. Kim KT, Jeong O, Jung MR, Ryu SY, Park YK. Outcomes of abdominal total gastrectomy for type II and III gastroesophageal junction tumors: single center's experience in Korea. J Gastric Cancer. 2012;12:36-42.

\section{Affiliations}

\section{Woo Jin Hyung ${ }^{1} \cdot$ Han-Kwang Yang ${ }^{2} \cdot$ Sang-Uk Han ${ }^{3} \cdot$ Young-Jun Lee ${ }^{4} \cdot J^{\prime}$ oong-Min Park ${ }^{5} \cdot$ Jin Jo Kim ${ }^{6}$. Oh Kyung Kwon ${ }^{7}$. Seong Ho Kong ${ }^{2} \cdot$ Hyoung-II Kim $^{1} \cdot$ Hyuk-Joon Lee $^{2}$. Wook Kim ${ }^{8}$. Seung Wan Ryu ${ }^{9}$. Sung-Ho Jin ${ }^{10}$. Sung Jin Oh ${ }^{11}$. Keun Won Ryu ${ }^{12}$. Min-Chan Kim ${ }^{13}$. Hye-Seong Ahn ${ }^{14}$. Young Kyu Park ${ }^{15}$. Young-Ho Kim ${ }^{16}$. Sun-Hwi Hwang ${ }^{17}$. Jong Won $\mathrm{Kim}^{5}$. Gyu Seok Cho ${ }^{18}$}

1 Department of Surgery, Yonsei University College of Medicine, Seoul, South Korea

2 Department of Surgery and Cancer Research Institute, Seoul National University College of Medicine, Seoul, South Korea

3 Department of Surgery, Ajou University School of Medicine, Suwon, South Korea
4 Department of Surgery, Institute of Health Sciences, Gyeongsang National University School of Medicine, Jinju, South Korea

5 Department of Surgery, Chung-Ang University College of Medicine, Seoul, South Korea

6 Department of Surgery, Incheon St. Mary's Hospital, The Catholic University of Korea College of Medicine, Incheon, South Korea 
7 Department of Surgery, Kyungpook National University Medical Center, Daegu, South Korea

8 Department of Surgery, Yeouido St. Mary's Hospital, The Catholic University of Korea College of Medicine, Seoul, South Korea

9 Department of Surgery, Keimyung University School of Medicine, Daegu, South Korea

10 Department of Surgery, Korea Cancer Center Hospital, Korea Institute of Radiological and Medical Sciences, Seoul, South Korea

11 Department of Surgery, Haeundae Paik Hospital, Inje University College of Medicine, Busan, South Korea

12 Center for Gastric Cancer, Research Institute and Hospital, National Cancer Center, Goyang, South Korea
13 Department of Surgery, Dong-A University College of Medicine, Busan, South Korea

14 Department of Surgery, Seoul National University Boramae Medical Center, Seoul, South Korea

15 Department of Surgery, Chonnam National University Hwasoon Hospital, Hwasun, South Korea

16 Department of Surgery, Kyung Hee University School of Medicine, Seoul, South Korea

17 Department of Surgery, Pusan National University Yangsan Hospital, Yangsan, South Korea

18 Department of Surgery, Soonchunhyang University College of Medicine, 170-Jomaru-ro, Bucheon-si, Gyeonggi-do, South Korea 